\title{
СПОСОБЫ ОБРАЗОВАНИЯ КОСВЕННОЙ ОСНОВЫ ИМЕНИ СУЩЕСТВИТЕЛЬНОГО В АВАРСКОМ ЯЗЫКЕ
}

\section{METHODS OF FORMATION OF THE INCOMPLETE STEM OF NOUNS IN THE AVAR LANGUAGE}

Z. Mallaeva

Summary: The article considers one of the most urgent and still argumentative issues of the Avar grammar, i.e. the problem of formation of the incomplete stem of nouns. The author suggests a new approach to classifying the types of incomplete stem, which more properly reflects the language matters. At the same time, the article also solves some important for Avar's morphology questions connected with the classification of the structures, forming incomplete stem, as well as grammar status of stem-formation elements.

The article also reveals the number of structural types of the root morphemes, depending on each of the stem-formation affixes. There are also described such phonetic processes connected with the incomplete stem-formation as root vowels exchange, syncope, accent changes, etc. All the conclusions are confirmed by a number of examples, thus proving the true results of the research.

Keywords: Avar language, indirect stem, noun, determinative suffix.
$\mathrm{M}$ орфемный строй аварского языка изучен только на уровне лексемной морфологии: установления структуры слова, классификации по частям речи, определения характера образования лексикограмматических единиц их парадигматики и синтагматики. С точки зрения структурной организации именная и глагольная лексема изучена относительно неплохо.

Иначе обстоит дело с морфемной морфологией. Не изучена структурная организация самой морфемыважнейшего элемента языка. Не установлена роль гласных в морфемообразовании. Этот факт, безусловно, свидетельствует об актуальности исследуемого вопроса. В данной статье мы преследовали цель - исследовать принципы образования косвенной основы имени существительного аварского языка. Строгого определения терминов морфема и корень нет, не только в научной литературе по аварскому языку, но и в целом в кавказоведении. На наличие данной проблемы также и в общем языкознании указывает В.А. Плунгян: «различие между корневыми и аффиксальными морфемами представляется интуитивно очевидным, но в действительности оно с трудом поддается формализации. Нам не известно ни одного эффективного определения корня и аффикса» [1, с. 81].
Маллаева Зулайхат Магомедовна

Д.филол.н., профессор, г.н.С., Институт языка, литературы и искусства имени Г. Цадасы Дагестанского федерального исследовательского чентра Российской академии наук, г. Махачкала.

logika55@mail.ru

Аннотация: В статье исследуется один и актуальных и нерешённых вопросов аварской грамматики - вопрос образования косвенной основы имени существительного. Предлагается новая классификация типов образования косвенной основы, адекватно отражающая языковые факты. Попутно решаются важные для морфемного строя аварского языка вопросы классификации структурных единиц, образующих косвенную основу. Определяется грамматический статус основообразующих элементов.

Выявляется, от какого структурного типа корневых морфем образует косвенную основу каждый из основообразующих суффиксов. Описаны фонетические процессы, имеющие место при образовании косвенной основы: различные чередования корневых гласных, синкопа (выпадение гласного между согласными), перенос акцентуации и т.д.

Наблюдения и выводы, содержащиеся в работе, подтверждаются достаточным количеством примеров, что обеспечивает достоверность полученных результатов.

Ключевые слова: аварский язык, косвенная основа, имя существительное, детерминативный суффикс.

Новой в данной статье является попытка определения типов косвенной основы, исходя из структурной организации корневой морфемы и детерминативного суффикса. Новым является также определение грамматического статуса основообразующих морфем, которые неоднозначно трактуются в авароведении. Теоретическая значимость статьи определяется постановкой и решением важных для авароведения вопросов основои морфемообразования. Материал статьи может быть применён при составлении сравнительно-исторической грамматики аваро-андо-цезских языков.

Первый опыт деления имен аварского языка на типы склонения принадлежит А. Шифнеру [2]. В основу типов склонения А. Шифнер кладет способы образования родительного падежа. Следует отметить, что этот принцип сохраняется и по сей день. Традиционно в аварском языке принято выделять множество способов образования косвенной основы имени существительного. Большинство исследователей придерживается классификации Г.И. Мадиевой [3, с. 73-74], которая выделяет в аварском литературном языке следующие восемь типов образования косвенной основы:

1. Именная основа остается без изменения, косвенная основа совпадает с прямой основой (оконча- 
ния присоединяются непосредственно к основе именительного падежа): бо «войско» - бо-ца, баба «мама» - баба-ца и т.д. На наш взгляд, косвенная основа в данном случае не представлена, речь, по всей видимости, идет здесь о прямой основе. Косвенная основа не может совпадать с прямой. Есть только два варианта: основа имени существительного может быть или прямой, или косвенной.

2. Косвенная основа образуется путем наращения гласных к форме именительного падежа (выделено нами - 3.М.): канн «лучина» - канн-а-ца; гьан «мясо» - гьана-ца и т.д. Здесь, очевидно, имеет место присоединение гласных к прямой основе, а не форме именительного падежа. Во-первых, смешиваются разноуровневые понятия: падеж и основа. Падеж относится к синтаксическому уровню языка, а основа - к морфемному и морфологическому. Во-вторых, не определён грамматический статус гласных -a-, у-, -о-, -и-, неясно, какую функцию они выполняют в данных примерах.

3. Косвенная основа образуется изменением конечного гласного исходной основы: ччугla «рыба»ччугlи-ча, чухъа «черкеска» - чухъи-ча, рагlи «слово» - paгlу-ца, лъади «жена» - лъаду-ца и т.д.

4. Наращение гласного $(a, u)$ сочетается выпадением гласного в исходной основе, но перед окончанием наращиваются гласные: гудур «капкан» - гудр$a-u a$, чluмих «камешек» - чluнх-u-ua, борохь «змея» - борхь-и-ца, каратl «дыра» - картl-u-ца, гlеретl «кувшин» - гlертl-и-ца и т.д.

5. Наращение гласного вызывает ассимиляцию корневого гласного: нус «нож» - нос-о-ца, муч «просо» - моч-о-ца, бел «лопата» - бол-о-ца, пер «лук» - пор-о-ца и т. д.

6. В косвенной основе меняются оба гласных исходной основы, например: бече «теленок» - бачu-ua, xlemle «нога» - xlaml-u-ua, чlopmo «тряпка»чlapm-и-ца и т.д.

7. Выпадение конечного звука сопровождается наращением слога -да, например: ццин «зло, гнев»цци-да-ца, лъим «вода» - лъа-да-ца, гІака «корова» - гlaк-да-ца.

8. Косвенная основа образуется путем наращения ряда слогов -за, -зу, -ро, -лу, -ду. -ву: мугъ «спина» - мугь-за-ца; кІал «рот» - кІал-зу-ца; нух «дорога» - нух-лу-ца; моцl «луна» - моцl-ро-ца; бо «войско» - бо-ду-л; си «башня» - си-ву-л и т.д. Здесь также неясен грамматический статус языковых единиц -да, $-3 a,-3 у,-p o,-л у,-\partial у .-в у$.

На наш взгляд, в аварском литературном языке можно выделить всего два типа образования косвенной основы. Первый тип из общепринятой в авароведении классификации основ отпадает, поскольку здесь нет косвенной основы, все примеры, приведённые автором, представляют прямую основу. Второй, третий, четвёр- тый, пятый и шестой типы можно объединить, поскольку во всех эти типах косвенная основа образуется одинаково: посредством вокалических суффиксов косвенной основы (-a-, -о-, -у-, -u-, -e-). В данных случаях принцип образования один и тот же. Внутри данного типа можно выделить подтипы, в зависимости от чередования корневых гласных.

Седьмой и восьмой типы также можно объединить, здесь косвенная основа образуется посредством детерминантов структуры СГ (-да-, -ду-,-3a-, -зу-, -ро-, -лу- ).

Следовательно, в аварском языке представлены два типа образования косвенной основы: 1) присоединением к корневой морфеме вокалических суффиксов косвенной основы: -a-, -о-, -у-, -u-, -е-; 2) присоединением к корневой морфеме основообразующих суффиксов структуры СГ: -да-, -ду-,-за-, -зу-, -ро-, -лу-.

В качестве вокалических суффиксов, образующих косвенную основу, в аварском языке употребляются все гласные:

-a-: бокь «хлев» - бокь- $a-$, канн «лучина» - канн- $a$-, гьан «мясо»- гьан-а-, цер «лиса» - цар- $а-$, халкъ «народ» - халкъ- $а-$, шавкъ «страсть»- шавкъ- $а-и$ т.д. -о-: гlус «зуб» - гlос-о-, мугь «зерно» - могь-о-, нус «нож» - нос-о-, гъветl «дерево» - гъотl-о-, кечl «песня» - кочl-о-, пер «лук» - пор-о-, оч «бык» - очo-; mleгь «цветок» - mloгb-о-, гьури «ветер»- гьор-о-, риди «сыворотка» - род-о-и т.д.

-у-: махх «железо» - махх-у-, нах «масло» - нах-у-, рагъ «война» - рагъ-у-, ракь - «земля» - ракь-у-, льади «жена»-льаду-, гlеч «яблоко»- гlеч-у-, гlарач «серебро» - гlари-у-, хІалтlu «работа» хlалml-y-, ицц «родник» - ицц-у-и т.д.

-u- $a x$ «сад» - $a x-u-$, ботl «вяз» - ботl-и, бече «теленок» - бач-и-, кьили «седло» - кьол-о-, кьибил «корень» - кьолб-о-, гариl «кузнечик» - гариl-u-, гулла «пуля» - гулл-и-, магl «гвоздь» - магl-u-, рохь «лес» - рохь-u-, xlemle «нога»-xlaml-u-.

-е-: ракl «сердие»-рекl-е-, иla «огонь» ule-.

Что касается грамматического статуса данных структурных единиц, неоднозначно трактуемых в авароведении, то их можно квалифицировать как основообразующие суффиксы или (по другой терминологии) детерминативные суффиксы, поскольку они детерминируют (определяют) косвенную основу имени существительного. Посредством детерминативного суффикса -а- образуют косвенную основу имена существительные с корневой морфемой двух структурных типов: СГС и СГСГС - это наиболее распространенные типы корневых морфем имени существительного, следовательно, детерминативный суффикс - $а$ - является самым распространенным суффиксом, образующим косвенную основу имени существительного. При образовании косвенной 
основы имени существительного посредством детерминативного суффикса - $а$ - наблюдаются следующие фонетические процессы:

1. чередование -е- $\rightarrow$-a-, обусловленное регрессивной ассимиляцией. Основообразующий суффикс - $а$ - уподобляет себе корневую гласную -е-, например: къед «стена» - къад- $а-$, гъеж «рука» - гъаж-а-; цер «лиса» - цар- $а$ - и т.д. При образовании косвенной основы от имен существительных с корневыми гласными - $a$ - и -у- фонетические процессы не наблюдаются, корневая морфема сохраняет свою структуру, например: ululad «дождь» ululad-a, гьaн «мясо»- гьан- $a-$ и т.д.

2. синкопа (выпадение гласного между согласными): гудур «капкан» - гудр-а -, кутан «плуг»кутн-а-, чакъал «шакал» - чакъл- $а$-, ригьин «бракосочетание» - ригьн- $a-$, хlухьел «пар» - хlухьл- $a-$, гьумер «лицо» - гьурм- $а$ - и т.д. Выпадение второго корневого гласного при образовании косвенной основы от имен существительных посредством детерминатива - $a$ - происходит в именах со структурой СГСГС. Во всех случаях основообразующий суффикс-а- является ударным.

Не менее распространено образование косвенной основы имени существительного посредством суффикса -и-. В отличие от суффикса -а- «употребление суффикса - U- не имеет структурных ограничений» [4, с. 17]. При образовании косвенной основы имени существительного посредством детерминативного суффикса -и- наблюдаются следующие фонетические процессы:

\section{1. аблаут: корневые -е- (реже -о-) $\rightarrow$-a-:}

При образовании косвенной основы при помощи суффикса -и- в именах существительных со структурой СГС корневая гласная -е- переходит в -а-, например: лъен «вилы» - лъан-и-, квен «еда»кван-и-, ххер «трава»-ххар-и-и т.д.

Корневые $a, u, y$, о за единичными исключениями (m/инчl «птенец» - mlaнчl-u) сохраняются в косвенной основе без изменений: хьаг «кастрюля» - хьаг-и-, хьит «обувь» - хьит-и-, заз «колючка»заз-и-, кlул «ключ» - кlул-и-и т.д.

2. аблаут: корневые -е- (реже -о-) $\rightarrow$-а- + синкопа: В именах существительных структуры СГСГ первая корневая гласная -е- или -о-, подвергается аблауту, вторая - синкопе, например: гъеду «ворона» - гъад-и-, кету «кошка» - кат-и-, xlemle «нога» - xlaml-u-, бече «теленок» - бач-u-, къоно «плита»-къан-и-, хоно «яйцо»-хан-и-и т.д. Если первая корневая гласная в двусложных именах существительных структуры СГСГ, СГССГ и СГСГС представлена -a-, -u- или -y-, она остается в косвенной основе неизменной, а вторая корневая гласная подвергается синкопе: хъаба «кувшин»хъаб-и-, гlанса «трость»- гlанс-и-, хъазан «котел»хъазн-и-, но: сордо «ночь» - сард-и- -о- $\rightarrow-$-и-)

\section{3) синкопа + синкопа:}

В многосложных именах существительных структуры СГСГСГ синкопе подвергаются сразу два гласных основы (последний и предпоследний), поскольку оказываются в безударной позиции в результате закрепления ударения на суффиксе косвенной основы -u-: гъадаро «тарелка» гъадр-и-, хІелеко «петух» - хІелк-и-, могоро «рычаг» - могр-и-, можоро «жребий» - можр-и- и т.д. При образовании косвенной основы односложных имён существительных структуры СГС, СГСС посредством суффикса -у- корневые гласные не изменяются, меняется только акцентуация - ударение переходит на суффикс косвенной основы: бакъ солнце»- бакъ-у-, рагъ «война»-рагъ-у-, гlemI «пот»- гleml-y-, гlор «река»- гlор-у-, хlарш «грязь»харш-у-, нах «масло» - нах-у-и т.д.

При образовании косвенной основы имён существительных структуры СГСГ, СГССГ, СГСГС посредством детерминативного вокалического суффикса -у- вторая корневая гласная подвергается синкопе: лъади «жена» - лъад-у-, ракъи «голод» - ракъ-у-, сали «песок» - сал-у-, рекьи «пахота» - рекь-у-, рокьи «любовь» - рокь-у-, гlарач «деньги»- гlари-у-и т.д.

Посредством суффикса -о- образуются косвенные основы от имён: а) структуры СГС: кор «общественная печь» - кор-о-, бел «лопата» - бол-о-; б) структуры ГС: оч «бык», «вол»-оц-о-;в) структуры СГСГ:бугlа «голозерный ячмень» - богl-о-; г) структуры СГССГ гlaum/u «топор» - гlouml-o-; д) структуры СГССГС: кьенссер «бровь»-кьонсср-о-, лачен «сокол»-лочн-о- , габур «шея»- горб-о- и др.

Односложные имена существительные образуют косвенную основу при помощи суффикса -о-, если они имеют в прямой основе корневые -e-, -у-, -о-, например: бел «лопата» - бол-о-, къверкъ «лягушка» - къоркъ-о-, тlегь «цветок» - mlozb-o-, $\mathrm{mlyml}$ «муха» - mloml-o-, гlус «зуб»гlос-о-, мугь «зерно»- могь-о- , оц «бык»-оц-о- и т.д.

При этом наблюдается делабиализация корневых лабиализованных согласных: гъветl «дерево» - гъотl-о-, къверкъ «лягушка»-къоркъ-о-и т.д.

Двусложные слова с конечными гласными при образовании косвенной основы теряют их: гьури «ветер» - гьор-о-, кьили - «седло» кьол-о-, риди «сыворотка» род-о-, жини «долото» - жон-о-, лага «тело, часть тела» - лог-о-, гlaщmlu «топор» - гlouml-о-, зани «надгробная плита», «межа»-зон-о- и т.д.

Двусложные слова с согласным исходом теряют гласный второго слога, например: хханжар «кинжал» - ххонжр-о-, габур «шея» - горб-о-, mlaгъур «шапка»mloгър-о- и т.д. Здесь имеет место метатеза согласных 
$(6 \rightarrow$ л): иluluбил «виноград» - и/цІолб-о-, хьибил «бок» - хьолб-о-, кьибил «корень» - кьолб-о-, сибил «угол» солб-о-.

При образовании косвенной основы двусложных имён существительных структуры СГСГС посредством суффикса -о- наблюдается чередование -и- $\rightarrow-0-$, обусловленное регрессивной ассимиляцией.

Посредством детерминативного суффикса - - образуют косвенную основу имена существительные с корневой морфемой следующих структурных типов: а) СГС: къор «капкан» - къор-и-, гьад «липа» - гьад-и-, заз «колючка» - заз-и-; б) СГСГ: гулла «пуля» - гулл-и-, хоно «яйцо» - хан-и-; в) СГСС: гвенд «яма» - гванд-и-, m/инчl «детеныш» - mlaнчl-u-, кlерт «ослёнок»- кlapm-u-. Корневые гласные имен структуры СГС и СГСГ при этом остаются неизменными, а корневая гласная имен структуры СГСС подвергается чередованию: $e \rightarrow a$ и $u \rightarrow a$.

Посредством детерминативного суффикса -е- образует косвенную основу только одна лексема [5, с. 123], это слово ракl «сердце» - рекl-е-.

В аварском языке представлены также основообразующие суффиксы имени существительного структуры

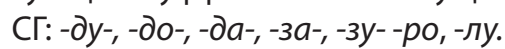

Посредством суффикса -ду- образуются косвенные основы имен существительных следующих структурных типов: а) [СГ]: би «кровь» - би-ду-, бо «войско» - бо-ду-, $x l e$ «воск» - xle-дy-, ula «огонь» - ula-дy, чу «лошадь»чо-ду- и т.д.; б) [СГС]: бекl «альчик» - букl-ду-, гохl «холм» - гохl-ду-, хер «трава» - хур-ду-, тlегь «цветок» - mlугьду- и т.д.; в) [СГССГ]: багІли «черешня» - багlли-ду-, бахча «огород» - бахча-ду-, гориlо «смородина» - гориlоду-, кваркьи «крыло» - кваркьи-ду- и т.д.; в) [СГСГ]: ракьа «кость» - ракьа-ду-, магьи «слоновая кость» - магьи-ду-, жага «вишня» - жага-ду-, ражи «чеснок» - ражи-ду- и т.д.; г) [СГСГССГС]: чlaкlулmlaн «свёкла» - чlaкlyлmla-дy-; д) [ГСГ]: ябу «кляча» - ябу-ду-.

У имен существительных с корневой морфемой на гласный ауслаут (структурные типы [СГ] и [СГСГ]) корневые гласные (-a-, -u-, -о-, -e-, - y-) остаются неизменными. М.Е. Алексеев допускает более поздний характер использования в литературном языке аффикса -ду-у этих имен. «Диалекты, как представляется, сохраняют более древнее состояние, ср. ражи «чеснок»- косв. осн.: лит. ражи-ду-, но анц. ножо-, андл. ружо- //рижи(последний вариант - результат выравнивания); жини «кайло» - ков. осн.: лит. жини-ду-, но анц. жоно-, андал. жоно- // жини-» [4, с. 22].

у имен существительных с корневой морфемой структуры [СГС] корневой гласный -о- (бох, гохl) не под- вергается изменениям при образовании косвенной основы. Корневой гласный -е- (бекl, хер, mleгь, ххеч, лъен) переходит в -у-. Если в ауслауте корневой морфемы структуры СГС представлены сонорные согласные $M, H_{\text {, }}$ то они подвергаются синкопе: u/ulyм «орел» - ululy-дy-;

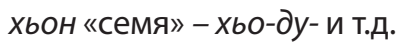

Посредством суффикса -да- образуются косвенные основы структурных типов: а) [СГС]: мухь «плата» - мухьда-, рахь «молоко» - рахь-да-, лбльим «вода» - льльа-да-; б) [СГСГ]: гlака «корова»-гlак-да-, мачlу «кремень»-мачlда-, рахъу «зола» - рахъ-да -; в) [СГССГ]: гІанкlу «курица» - гlaнкly-дa-.

Предстоит выяснить в случаях с примерами лълъим «вода» - лблъа-да- и ицин «желчь» - цци-да- (диал. циада-) чем является консонант -д-: компонентом основообразующего суффикса -да- или компонентом корневой морфемы, полученным в результате перехода -м и -н в -д-. Как нам представляется, в данных примерах -д- является компонентом корневой морфемы, полученный в результате чередования - $-\mathbf{-} \rightarrow-\partial-$ и - $-\rightarrow-\partial-$.А.С. Чикобава и И.И. Церцвадзе также обращают внимание на двойственный характер компонента -д- в примерах. В большинстве случаев компонент -д- является «вставочным согласным», который наращивается к косвенной основе (рахь - рахь-да- «молоко»), в другом - является результатом чередования конечного согласного прямой основы

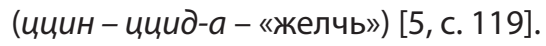

Посредством суффикса -до- образуются косвенные основы лишь двух имён существительных: квер «рука»ко-до- и зоб «небо» - зо-до-. В первом случае (квер - кодо-) происходит делабиализация анлаутного согласного и синкопа ауслаутного. Во втором случае - синкопа ауслаутного согласного.

Посредством суффикса -зу- образуются косвенные основы имен существительных следующих структурных типов: а) [СГС]: бер «глаз» - бер-зу-, гlин «ухо» - гlин-зу-, кІал «рот» - кlал-зу-, кlветl «губа» - кlветlал-зу-, мачlul «язык»- мац/ulал-зу-, рач/чl «хвост» - рач/чlал-зу- и т.д.; б) [СГСГ]: нодо «лоб» - надал-зу-, наку «колено» - накал-зу-, нилъу «подбородок» - нилъал-зу-, mluну «дно» - mlиналзу-; в)[СГСГС]: керен «грудь» - каран-зу-; г) [СГГС]: гьуэр «легкое»- гъуъру-зу-; д) [ГСГ] эгъе «пятка» - агъал-зу-и т.д.

Как видим, основная часть этих лексем относится к соматизмам. Ещё П.К. Услар отмечал, что среди всех суффиксов, образующих косвенную основу, более распространён показатель -зу-, встречающийся в названиях частей тела [6, с. 58]. М.Е. Алексеев считает, что «сюда следует отнести и мугъ-за- с изменённым вокализмом, косвенная основа образуется с помощью только -зу- в небольшом числе слов, оканчивающихся на сонорный (керен «грудь», кІал «рот», гlин «ухо», бер «глаз»), оформ- 
ляясь в большинстве случаев сложным суффиксом -алзу-. Первый компонент этого суффикса формально совпадает с показателем множественности и с окончанием генитива (- $a-$ - суффикс косвенной основы, -л - суффикс генитива). В целом представляется правдоподобной связь этого компонента и с тем, и с другим аффиксом, однако в данных примерах ударность -ал- позволяет отдать предпочтение форме генитива (суффикс косвенной основы - $а$ - всегда ударный, в то время как суффикс множественного числа -ал, как правило, безударный). Что касается элемента -зу-, то его происхождение можно увязывать с суффиксом -аз-, маркирующим косвенную основу множественного числа» [4, с. 18]. Элемент -з- в суффиксе -аз-, маркирующем косвенную основу множественного числа, А.С. Чикобава и И.И. Церцвадзе считали фонетическим вариантом суффикса -д-» [5, с. 121].

Посредством суффикса -за- образует косвенную основу лишь одна лексема: мугъ «спина» - мугъ-за-. Суффиксы -ро и -лу также встречаются в единичных случаях: моцlul «луна» - моulul-ро-, нух «дорога» - нух-лу-. Среди основообразующих суффиксов структуры СГ наибольшее распространение получили суффиксы -ду-, -да-.

Проведенный в статье анализ позволяет сделать следующие выводы:
1. В аварском литературном языке следует выделить два типа образования косвенной основы имени существительного. Первый тип представляет собой образование косвенной основы посредством присоединения к корневой морфеме вокалических детерминативных суффиксов. Второй тип представляет собой образование косвенной основы посредством присоединения к корневой морфеме детерминативных суффиксов структуры СГ.

2. В качестве вокалических суффиксов, образующих косвенную основу, в аварском языке употребляются все гласные: - $a-,-0-,-y-,-u-,-e-$. Основообразующие суффиксы структуры СГ представлены следующими единицами: -да-, -ду-,-за-, -зу-, -ро-, -лу-.

3. Данные структурные единицы, неоднозначно трактуемые в авароведении, получили в статье грамматический статус, исходя из выполняемой ими функции: они квалифицируются как основообразующие или детерминативные суффиксы.

4. Среди вокалических суффиксов наибольшее распространение получил детерминативный суффикс - $a$-, наименьшее - суффикс - - - (только в одном слове). Среди суффиксов структуры СГ наибольшее распространение получили -ду- и -да-, наименьшее - -ро и -лу- (встречаются в единичных случаях).

\section{ЛИТЕРАТУРА}

1. Плунгян В.А. Общая морфология: Введение в проблематику. М.: Эдиториал УРСС, 2000.

2. Schiefner A. Versuch über das Awarische // Memoires de I'Academie

3. imp. St. Petersbourg, 1862. T. 5. N 8. Ser YI1I.

4. Мадиева Г.И. Морфология аварского литературного языка. Махачкала, 1981.

5. Чикобава А.С., Церцвадзе И.И. Аварский язык. Тбилиси, 1962. На груз. яз.

6. Алексеев М.Е. Сравнительно-историческая морфология аваро-андийских языков. М., 1988.

7. Услар П.К. Этнография Кавказа. Языкознание. IV. Аварский язык. Тифлис, 1889.

○ Маллаева Зулайхат Магомедовна (logika55@mail.ru). 